\title{
Semiosis and pragmatism: Toward a dynamic concept of meaning
}

\author{
João Queiroz, Floyd Merrell \\ Research Group on History, Philosophy, and Biology Teaching, \\ Institute of Biology, Universidade Federal da Bahia (UFBA), Brazil ${ }^{1}$ \\ e-mail: queiroz@gmail.com \\ Department of Foreign Languages and Literature \\ Purdue University, West Lafayette, IN, USA \\ e-mail: fmerrell@purdue.edu
}

\begin{abstract}
Philosophers and social scientists of diverse orientations have suggested that the pragmatics of semiosis is germane to a dynamic account of meaning as process. Semiosis, the central focus of C. S. Peirce's pragmatic philosophy, may hold a key to perennial problems regarding meaning. Indeed, Peirce's thought should be deemed seminal when placed within the cognitive sciences, especially with respect to his concept of the sign. According to Peirce's pragmatic model, semiosis is a triadic, time-bound, context-sensitive, interpreter-dependent, materially extended dynamic process. Semiosis involves inter-relatedness and inter-action between signs, their objects, acts and events in the world, and the semiotic agents who are in the process of making and taking them.
\end{abstract}

Pragmatism $^{2}$, in its original formulation, can be defined as a theory of meaning. ${ }^{3}$ At first developed by C. S. Peirce, in the 1870 s, in the ambience of a series of informal meeting under the guise of the Meta-

\footnotetext{
1 Also: Department of Computer Engineering and Industrial Automation, FEEC; University of Campinas, Campinas-SP, Brazil.

2 We haved decided to use the more general term 'pragmatism', instead of the more specific, Peircean based term, 'pragmaticism', since our discussion includes 'pragmatic' philosophers other than Peirce.

We write 'original formulation' in order to differentiate between the strain of pragmatism that will be the focus of this inquiry and the more recent strain, often going by the name of 'neopragmatism', among the most notable proponents of which are Richard Rorty $(1979 ; 1982)$ and Donald Davidson (1984).
} 
physical Club at Harvard (see Fisch 1986), the theory is publicly presented by William James in 1898 (Philosophical Conceptions and Practical Results), and thereafter formulated by John Dewey and F. C. S. Schiller. Despite the fact that Peirce continued to refer to pragmatism as an 'old idea', and include, among its precursors, Socrates, Aristotle, Spinoza, and Kant, John Locke was in fact the first philosopher to precisely formulate a semiotic (pragmatic) theory of meaning (Waal 2001: 24).

Conceived as strictly a 'logical principle', Peirce is against the transformation of pragmatism into a speculative philosophical attitude (Hookway 2004). At the same time, Peirce's pragmatism bears affinity with Ludwig Wittgenstein's later philosophy as a means of clarifying philosophical problems — most of which are pseudoproblems - and of ignoring genuine problems or paradoxes that allow for no apparent solution, at least with respect to pragmatism's 'logical principles'. As a matter of fact, scholars of pragmatism and Wittgenstein orientation tend to oscillate between what they consider 'logical principles', 'methods', and 'rules'. Their philosophical thrust is 'therapeutic' rather than 'doctrinaire', and if the pragmatic philosopher is an architectonic system builder, he nevertheless concedes that an absolutely final product, complete and free of all inconsistencies, can hardly be at hand, given (1) the concrete, practical affairs of pragmatism, and (2) our human fallibilism (Chisholm 1952).

Introduced in 1878 in 'How to make our ideas clear', Peirce defines pragmatism as a rule to clarify ideas, concepts, and propositions. In a latter essay published almost thirty years later in The Nation (1907), Peirce describes the central core of pragmatism in these conditional terms: 'The full meaning of a conceptually grounded predicate implies certain types of events that would likely occur during the course of experience, according to a certain set of antecedent conditions' (CSP-MS 318; CP 5.468). ${ }^{4}$ What, in this vein, is the most appropriate means of introducing pragmatism? In his Harvard Lectures

4 Following the scholarly tradition, Peirce's work will be referred to as CP (followed by volume and paragraph number for quotes from The Collected Papers of Charles S. Peirce, Peirce 1866-1913), EP (followed by volume and page number for quotes from The Essential Peirce, Peirce 1893-1913), MS (followed by reference number in accordance to Peirce 1967 for quotes from Peirce's manuscripts), and W (followed by volume and page number for quotes from Writings of Charles S. Peirce, Peirce 1839-1914). 
of 1903 Peirce chose to introduce his philosophical posture through examples from what he called 'normative science'. He based the organization of these examples on the what we will label the concepts of inter-relatedness and inter-action between signs, the world, and interpreters.

Semiosis implies process. In this regard, we follow Rescher in his definition of a process as "[...] a coordinated group of changes in the complexion of reality, an organized family of occurrences that are systematically linked to one another either causally or functionally" (Rescher 1996: 38). Semiotics entails the project of 'cutting' minute portions of the process and actualizing them as signs for observation, formal study, analysis, and synthesis. The result, historically, brought about the spectrum of human intellectual endeavors including mathematics, logic, the physical and biological sciences, the social sciences, and philosophy and the 'normative sciences' (aesthetics, ethics, logic) (see Parker 1998; Potter 1997). The entire range of these intellectual semiotic endeavors, as well as the semiotics of everyday life including feelings, emotions, and concepts, make up the whole of human semiotics, carved out of the semiosic continuum.

\section{Peirce's concept of semiotics}

Peirce's concept of Semiotics as the 'formal science of signs', and the pragmatic notion of meaning as the 'action of signs' (semiosis), have had a deep impact in philosophy, psychology, theoretical biology, and cognitive sciences (see Jakobson 1960; Thom 1975; Prigogine, Stengers 1983; Freeman 1983; Fetzer 1988; 1997; Colapietro 1989; Tiercelin 1995; Hoffmeyer 1996; Houser et al. 1997; Brunning, Forster 1997; Deacon 1997; Freadman 2004; Hookway 2002; 2004; Misak 2004; Pietarinen 2005; Magnani 2007; Stjernfelt forthcoming). First and foremost, Peirce's semiotics is grounded on a list of categories Firstness, Secondness, Thirdness - which corresponds to an exhaustive system of hierarchically organized classes of relations (Houser et al. 1997). This system makes up the formal foundation of his philosophy (Parker 1998) and of his model of semiotic action (Murphey 1993: 303-306).

In brief, the categories can be defined as: (1) Firstness: what is such as it is, without reference to anything else; (2) Secondness: what 
is such as it is, in relation with something else, but without relation with any third entity; (3) Thirdness: what is such as it is, insofar as it is capable of bringing a second entity into relation with a first one in the same way that it brings itself into relation with the first and the second entities. Firstness is the category of vagueness, freedom, novelty and originality - 'firstness is the mode of being which consists in its subject's being positively such as it is regardless of anything else. That can only be a possibility' (CP 1.25). Secondness is the category of reaction, opposition, differentiation, existence - 'generally speaking genuine secondness consists in one thing acting upon another, brute action' [...] 'I consider the idea of any dyadic relation not involving any third as an idea of secondness' (CP 8.330). Thirdness is the category of mediation, habit, generality, growth, and conceptualization or cognition (CP 1.340). In another way of putting the categories: Firstness is possibility, what might become, Secondness is what is taken to be what is within some particular context, and Thirdness is what in all probability would be, given a certain set of conditions (for further on categories, see Hookway 1985; Murphey 1993; Potter 1997).

\subsection{The Peircean sign}

Peirce defined semiosis as an irreducible triadic relation between a Sign, its Object (the object, act or event with which it inter-relates) and its Interpretant (that which is becoming interpreted through its inter-action with its interpreter) - we will hereafter refer to this sign triad as $S, O$, and $I$ (CP 2.171, CP 2.274). That is, according to Peirce, any description of semiosis involves a relation constituted by three irreducibly connected terms, which are its minimal constitutive elements (MS 318:81; CP 2.242). In Peirce's words:

My definition of a sign is: A Sign is a Cognizable that, on the one hand, is so determined (i.e., specialized, bestimmt) by something other than itself, called its Object, while, on the other hand, it so determines some actual or potential Mind, the determination whereof I term the Interpretant created by the Sign, that that Interpreting Mind is therein determined mediately by the Object. (CP 8.177; emphasis in the original) 
Peirce conceives a 'Sign' or 'Representamen' as a 'First' $(S)$ which stands in a genuine triadic relation with a 'Second', called its 'Object' $(O)$, which is in the process of 'determining a Third', called its 'Interpretant' $(I)$, which assumes the same triadic relation with that Object (CP 2.274). The triadic relation between $S, O$ and $I$ is regarded by Peirce as irreducible, in the sense that it is not decomposable into any simpler relation. Thus the term 'sign' was used by Peirce to designate the irreducible triadic process between $S, O$ and $I$ as well as to refer to the first term of the triad. Some commentators proposed that we should distinguish between the 'sign in this strict sense' and the 'sign in a broad sense' (e.g., Johansen 1993: 62). Signs, conceived in the broad sense, are never alone. The triadic process of sign making and sign taking is just that: process.

\subsection{The sign process}

As Savan (1986: 134) argues, an interpretant is both the third term of a given triadic relation and the first term (sign) of a subsequent triadic relation. This is the reason why semiosis cannot be defined as an isolated triad; it necessarily involves the continuous development of triads actualized from semiosis (see Merrell 1995). In Savan's (19871988: 43) words, the terms interpretant, sign and object compose a triad whose definition can only be circular; each one of the three terms is defined by the other two. The only properties to be found in $S, O$ and $I$ are in the functional role; there is no distinct essential or substantive property, for at any given instant what was an $S$ can become an $O$ or an $I$, and the same can be said of $O$ and $I$ (Tienne 1992).

Indeed, one of the most remarkable characteristics of Peirce's theory of signs is its dynamical nature. The complex $(S-O-I)$ is the focalfactor of a dynamical process (Hausman 1993: 72). As a truly process thinker, it was quite natural that Peirce conceived semiosis as basically a process in which triads are systematically linked to one another so as to form a web. Sign processes are inter-relatedly extended within the spatiotemporal dimension, so that something physical has to instantiate or realize them. This means that signs cannot act unless they are spatiotemporally realized (see Emmeche 2003; Deacon 1999). If a sign is to have any active mode of being, it must be materially embodied. 


\subsection{Meaning and semiosis}

Peirce defined meaning as the consequence of triadic inter-relations of $S-O-I$ as a whole (EP 2:429), as well through differential correlates among the sign, the object (MS 11, EP 2:274), and the interpretant (EP 2:496, EP 2:499; CP 4:536) (see Fitzgerald 1966: 84; Bergman 2000). This notion of meaning is derived from his definition of the sign as a medium for the communication of a form or a habit embodied in the object to the interpretant, so as to determine the interpreter's behavior through inter-related inter-action with the sign (see Tienne 2003; Hulswitt 2001; Bergman 2000). Peirce spoke of the sign as a 'conveyer', as a 'medium' (MS 793), as ‘embodying meaning'.

A Sign may be defined as a Medium for the communication of a Form. [...] As a medium, the Sign is essentially in a triadic relation, to its Object which determines it, and to its Interpretant which it determines. [...] That which is communicated from the Object through the Sign to the Interpretant is a Form; that is to say, it is nothing like an existent, but is a power, is the fact that something would happen under certain conditions. (MS 793: 1-3; EP2, p. 544, n. 22)

In short, for Peirce a sign is both 'a Medium for the communication of a Form' and 'a triadic relation, to its Object which determines it, and to its Interpretant which it determines'. If we consider both definitions of a sign, we can say that semiosis is a triadic process of communication of a form from the object to the interpretant by the sign mediation.

\subsection{Form communication}

Form is defined as having the 'being of predicate' (EP 2.544) and it is also pragmatically formulated as a 'conditional proposition' stating that certain things would happen under specific circumstances (EP 2.388). But for Peirce, form is nothing like a 'thing' (Tienne 2003), but something that is embodied in the object (EP 2.544, n. 22) as a habit, a 'rule of action' (CP 5.397, CP 2.643), a 'disposition' (CP 5.495 , CP 2.170), a 'real potential' (EP 2.388) or, simply, a 'permanence of some relation' (CP 1.415).

Form can also be defined as potentiality ('real potential', EP 2.388). If we consider this definition, we will also come to the conclu- 
sion that form can show the nature of both firstness and thirdness. Consider that potentiality is not the same as mere possibility. For the sake of our argument, consider Peirce's treatment of Quality as a 'mere abstract potentiality' (CP 1.422). It is abstraction not in the sense of a reduction of complexity to formal simplicity, but in the sense that the quality in question has been 'abstracted' ('cut') from the continuum of possibilities.

Quality, then, has the nature of Firstness, being essentially indeterminate and vague. But we can also talk about a generality of Quality. In this case, we are beyond the domain of pure Firstness, since generality refers to some law-like tendency. Peirce works in this case with a merging of Firstness and Thirdness. As an abstract potentiality, Quality is closer to a blend of Firstness and Thirdness, than to pure Firstness. Such a treatment seems to be compatible with Peirce's categorical scheme, since, as Potter (1997: 94) stresses, the categorical structure which Peirce uses is 'highly subtle and complex, admitting of various combinations'.

For Murphey, there is a transition from the notion of meaning as a qualitative conception carried by a sign to a relational notion according to which the meaning of a concept consists in a 'law relating operations performed upon the object or conditions of perceptions to perceived effects' (Flower, Murphey 1977: 589). The qualitative conception involves reference to the sign's ground, while the 'law' or necessary conditions of perception are relational rather than qualitative - 'If the meaning of a concept of an object is to consist in the conditionals relating operations on the object to perceived effects, these conditionals will in fact be habits' (Flower, Murphey 1977: 590).

This brings about a constrained set of effects of the Object on the interpreter through the mediation of the Sign. In short, Peirce defines a Sign both as 'a Medium for the communication of a Form' and as 'a triadic relation, to its Object which determines it, and to its Interpretant which it determines'. If we consider both definitions of a Sign, we can say that semiosis is a triadic process of communication of a form from the Object to the Interpretant by the Sign mediation. 


\subsection{The emerging process as form-becoming}

Meaning can also be conceived as the emergence of a process involving $S, O$ and $I$ through mediation of $I$. It can be seen as a process working as a constraining factor of possible patterns of interpretative behaviors. Taking the notion of a form into account, an understanding of meaning becomes a dynamic, processual inter-action by the interpreter of a sign through co-participation between that sign and the interpreter. A possible form emerges through this mutual co-participation. In this manner a genuine sign without a co-participant is meaningless. Since the sign maker and taker as interpreter emerges out of co-participation with the sign, the existence of a possible form is embodied in $S, O$ and $I$, and a habit is intrinsic to the sign and the interpreter acting on the sign. This entails a constrained set of effects on the interpreter that can be fruitfully connected to Rosenthal's (1994) pragmatic approach to meaning as an emergent relational pattern of behavior. $^{5}$

The form-becoming is the realization of a habit of inter-action embodied in the Object to the interpreter so as to constrain its behavior. This brings about a constrained set of effects of the Object on the interpreter through the mediation of the Sign.

\section{Habit forming}

It is well known among Peirce scholars that habit occupies a central position in Peirce's pragmatism (for a summary see Almeder 1980; Hookway 1985). Peirce's habit entails a disposition to act in a certain ways under certain circumstances, especially when the carrier of the habit is stimulated, animated, or guided by certain motives (CP 5.480). The meaning of a Peircean sign is most adequately understood through the habits of action, reaction, and thought they provoke, sustain, and modify in the event that the habit carrier wishes to bring about a change of the customary response to a given sign. When

\footnotetext{
5 The term 'emergence' has both an ordinary use, in which people employ the expression 'the emergence of $x$ ' just to mean that ' $x$ has appeared', and a technical use. Stephan (1998: 639) writes that "in most technical uses, "emergent" denotes a second order property of certain first order properties (or structures), namely, the first order properties that are emergent' (see Queiroz, El-Hani 2006).
} 
somebody says a diamond is 'hard', that person means that a diamond's nature includes the ability to cut glass and other substances. That person's disposition to conceive of a diamond in this way rather than simply conceiving it for ornamental purposes - constitutes, pragmatically, what 'hardness' means, and 'diamond' means in terms of its characteristics and its nature. In this manner, a sign (triadically) communicates a habit (potentiality, disposition) embodied in the object to its interpretant. If this person in question had once considered diamonds strictly in terms of rare gems, and ornamentation, then the characteristics and nature of diamonds were previously something other than they now are. Consequently, the meaning of 'diamond', and the habit of deriving such meaning, changed when a diamond became a means for qualifying 'hardness'. This is to say that the notion of semiosis as form communicated from $S$ to $O$ to $I$ through mediation allows us to conceive of semiosis, and meaning and meaning change, in a non-substantive, processual way, as a constraining factor of possible patterns of interpretative behavior through habit and change of habit.

\section{Distinguishing Peirce from other theories of signs and their meaning}

\subsection{Frege's legacy}

Classical theories of reference assume a strong connection between a sign, its meaning, and its reference. Knowing the meaning of a sign is knowing how it refers. Gottlob Frege simplified this formula (Frege 1970; Dummett 1972). He drew a distinction between 'sense' (Sinn) and 'reference' (Bedeutung). 'Sense' is grasped when a sign is understood, and this 'sense' determines its 'reference'. Frege is often regarded as the prime initiator of 'logicism' — the wedding of logic and mathematics, with the former hopefully becoming the repository of all thought and the latter the queen of the sciences. According to Frege, if language could be liberated from vagueness and ambiguity, it could become a respectable instrument of unequivocal meaning and thought. In other words, by 'logicizing' language, its weaknesses could be strengthened, its blemishes could be erased, and future mistakes could be avoided. From the Olympian reaches of the highest rooftops the world could eventually be seen from a detached God's-eye view. 
The task Frege set for himself by way of this 'sense/reference' distinction was monumental: to establish a method for determining linkages between the objective world and its representation in signs. Equality of meaning of different signs referring to the same object became the watchword. The dilemma was that Frege's grand game plan involved rendering two virtually incompatible domains virtually equivalent: language on the one hand, and the furniture of the world on the other. Frege argued that while two signs with the same 'reference' - Venus, for example - could have two senses - the 'morning star' and the 'evening star' - two signs with the same sense could not enjoy the luxury of different 'reference'. By way of definitions, the intension (sense) of a sign consists of the conception of the sign, irrespective of that to which it refers. Extension (reference) consists of the things to which that conception refers. Intension used in this context must be distinguished from intension (of intensionality), a phenomenological term entailing the property of consciousness whereby it refers to or intends an object. The intensional object is not necessarily existent, but can be merely what the mental act is about, whereas extension presumably involves the 'real' furniture of the objective world (Avni 1990).

Thus, 'Venus is Venus' is a tautology. In contrast, 'That star up there in the dark expanse is Venus' is not. It bears reference, extension. 'The evening star is Venus' has both reference and sense, intension. But 'The morning star is Venus' also spots reference and sense. Reference is one ('Venus') but sense is two ('evening star', and 'morning star'). However, Frege assures us that no problem exists inasmuch as we specify 'reference' to objects in the physical world, so it is still smooth sailing toward clear and distinct thinking and meaning. Apparently the relations between Frege's signs and the world is not that of symmetry, but asymmetry. However, this problem was in a manner of speaking pushed under the rug, for the sign's intensionality (sense) was highlighted somewhat at the expense of extensionality (reference), and language itself, that apparently ubiquitous partner to mind, held the trump card. Which is what we might have expected, since Frege stacked the deck from the beginning.

But more questions arise: Do sentences impart any information regarding their presumed objects of 'reference' (Venus, morning star, evening star), or simply about the signs themselves ('Venus', 'morning star', 'evening star')? If the latter is the case, then how comes it 
that we would like to be comforted by the soothing idea that 'reference' is fixed, while meanings may suffer alterations? If meanings change, how can signs actually 'refer to' the same things in the world? If signs do not necessarily 'refer to' the same things but to variable 'semiotic entities', then do the 'real' things of the world actually make much difference regarding the engendering of meaning? Can meanings be something found in things 'referred to', or are meanings embodied within their respective signs? Or in the final analysis, do words hook onto world.

\subsection{Saussure}

The Swiss linguist whose life parallels that of Peirce eschews diachrony and develops a tunnel-minded obsession with synchrony. Language, at a particular synchronic slice, is conceived to be virtually immutable; it is for the purpose of analytic practice a bedrock of order and stability. According to this notion, meaning remains fundamentally the same independently of any and all individual sign users with specific contexts; language is no slave to the wishes and whims of the individual; if change there be, it comes about through the linguistic practices of the entire community. Language is ultimately grounded in rock-solid objectivity. It must exist outside all individual consciousness in order that there might be communication at all; yet at the same time it must be ready and available to any and all speakers, who in the beginning internalized it, and as individuals, are now slaves to language, unlike Humpty-Dumpty whose words mean exactly what he wants them to mean (Saussure 1966).

Language study in terms of a static, autonomous synchronic slice divorced of the evolutionary history of language carries the implication that: (1) there is little to no consideration of time, (2) language is self-sufficient and has no need of the physical world and lines of correspondence between signs and objects, (3) meaning is constructed exclusively within language, (4) meaning, derived from a signifier/signified binary relationship, is in the brain-mind of the speaker and hearer, and to the entire speech community to which they belong, (5) consequently there is no legitimate appreciation of the process of sign development and evolution of signs (Harris 1987). 
In sum, if we take Saussure at face value, we have hardly more recourse than to toss time, process, change, history, and the idea of contextuality, in the trash heap. Understandably, Saussure has come under attack in recent decades from a variety of views (Derrida 1974; Harris 2002; Thibault 1996).

\subsection{Information theory}

The mathematical theory of communication is a branch of mathematics that arose out of communication theory. As Shannon and Weaver defined it, "[t]he fundamental problem of communication is that of reproducing at one point either exactly or approximately a message selected at another point' (Shannon, Weaver 1949: 31). According to Adams (2003: 472), 'at the foundation of information theory is the development of methods to measure the amount of information generated by an event or events, and mathematical treatments of the transmission characteristics of communication channels'. It relies on the theory of probability to model information sources, flow, and communication channels. Information is measured in terms of the unexpectedness of the sequence of signals, written $H=\boldsymbol{\Sigma} p_{i} \log \left(1 / p_{i}\right)$, where $p_{i}$ is the probability of the $i$ th form of signal.

This theory allows one to define information as the measure of the probability of selection of a particular message among the set of all possible messages. The probabilistic measure of information provided by this theory is non-semantic, indifferent to meaning (Shannon, Weaver 1949: 31).

A sign is decoded by the emitter and transmitted through a medium, then encoded by the receiver. The medium can be compact and diffuse air patterns between speaker and listener, black marks on paper between writer and reader, or electrical impulses between telephone messages sent and messages received. Francisco Varela calls this the 'conduit tube' theory (1979). It is as if the emitter sent signs through a conduit tube and they are received by the receiver, and, if by some miracle the receiver takes in an exact replication of those signs, meaning is preserved. But actually, there virtually no regard for meaning in information theory. Rather, information theory is based on the statistical probability of a set of signs creating an intelligible combination, a relatively intelligible combination in spite of some back- 
ground noise, or of the set become a mere scramble, noise. Meaning is by and large ignored.

\subsection{Kripke}

Kripke generally follows the 'causal theory' of reference according to which the object 'causes' particular mental events that then call up meaning (Kripke 1972; 1977; 1980). In some way, 'the referent must be historically, or, we might say, causally connected to the speech act' (Donellan 1972: 377). The causal theory explains the power of words in their referring to objects in terms of causal chains that include the objects of signs and the speaker's and hearer's representations of them. A singular sign 'rigidly designates' a particular object; this designation is a matter of the appropriate causal links holding between the object and the sign's use. This theory 'seems to promise not only a unified treatment of the various object-involving phenomena [by way of knowledge, memory, belief, empirical evidence], but a naturalistic and possibly even physicalist one as well' (Stampe 1979: 87).

This is an 'objectivist-realist' view (in this regard see Kripke's (1982) reaction to Wittgenstein's skeptical argument). Consequently, imaginary signs, or fictions, cannot work like objectivist linguistic constructions. If they did, there would be no knowing whether or not life is just a dream. But it is not a dream, according to the objectivistrealist, for the world is real. And this reality is accessible, if we could just get things right by correctly hooking worlds onto the furniture of the world. Representation, reference, and meaning, then, are quite legitimate. There is according to this theory definitely a correspondence between language and objects, acts, and events. The upshot is that meaning is derived from this dualistic combination of sign and thing. Context is consequently given little consideration (Hacking 1993).

\subsection{Lakoff and Johnson}

Understanding entails the world we made, our semiotic world, and the way we experience it. Such understanding involves body and mind as a whole, as bodymind, and our capacities and skills, values, moods and attitudes, within our entire cultural tradition. Meaning as a body- 
mind process is a matter of creating 'schemes' as models of knowing and meaning making (Johnson 1987; Lakoff 1987). 'Schemes' involve the way we are bound up within a linguistic community, our aesthetic sensibilities, logical and rational modes of comprehending out world, and our ethical standards.

Understanding entails, in this manner, and to use the terms of our argument, our inter-active, inter-relatedness with and from within our world, our cultural institutions, our linguistic tradition, and our historicized context. It is our concretely sensed world as well as our world of abstractions. The whole of our contextualized understanding comes to bear on the meaning we arrive at with respect to each and every sign (Lakoff, Johnson 1999). We would tend to concur at least with this aspect of Lakoff and Johnson's general view of meaning, and it is by and large commensurate with Peirce's thought.

\section{In capsule form}

Table 1 offers a schematic picture of the diverse concepts of meaning since Frege's time. A study of the similarities and contrasts among the capsules making up the scheme leads one to the observation that solely the Peircean Mode, (1) adequately accounts for semiosicsemiotic processes in time in terms of past-present-future, (2) correlates time with three forms of semiosis according to the nature of the categories, (3) considers differences (a) between the components of the sign, (b) between signs and other signs, (c) between the categories, (d) between mind, body and world, and (e) 'in here' and 'out there' and empirical and non-empirical, as a matter of degree rather than kind, dynamic potential continuity rather than static discontinuity, process rather than product, (4) embodies the mind, and the embodied mind is involved to a greater or lesser degree according to the sign type and the category or categories in question, and (5) genuinely includes context dependency of signs, their objects, their interpretation, and their interpreters - since those interpreters are, themselves, signs among signs. The five non-Peircean theories encapsulated in Table 1 account for at least one or more of the five qualifications, but only Peirce's concept of the sign and meaning includes all of them. 


\begin{tabular}{|c|c|c|c|}
\hline 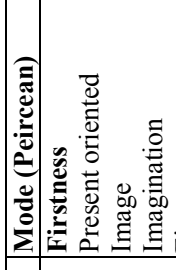 & 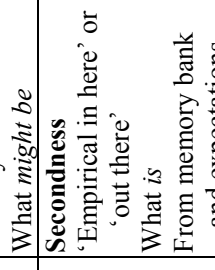 & 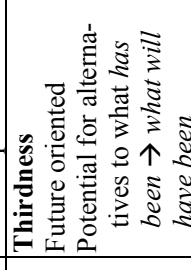 & 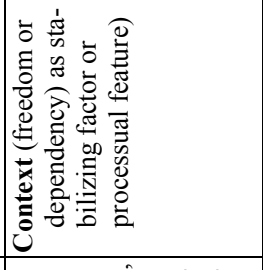 \\
\hline 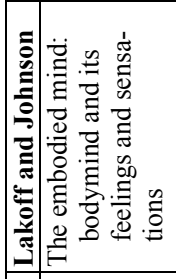 & 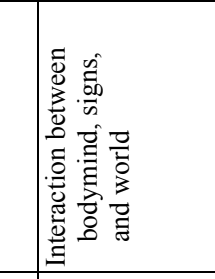 & 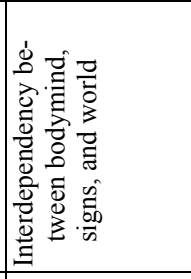 & 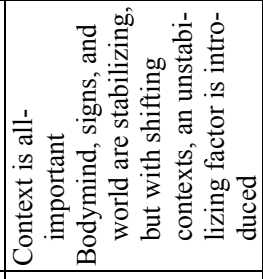 \\
\hline 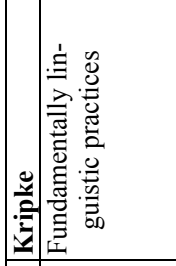 & 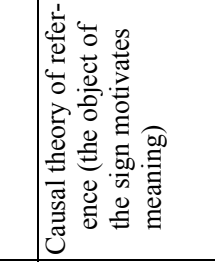 & 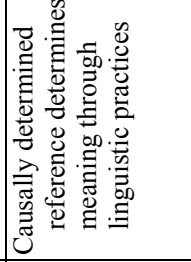 & 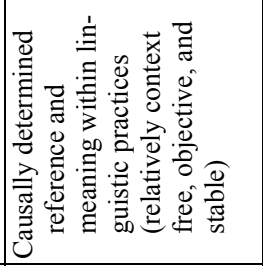 \\
\hline 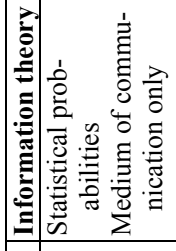 & 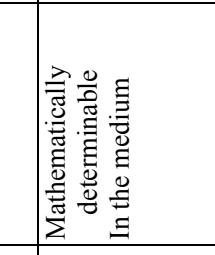 & 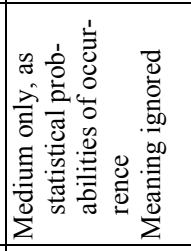 & 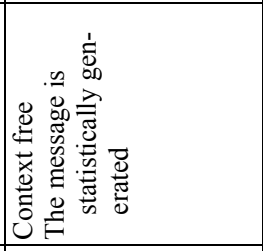 \\
\hline 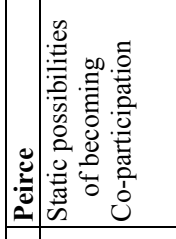 & 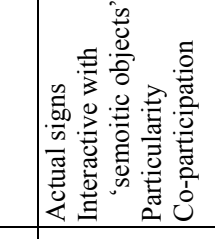 & 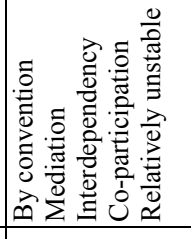 & 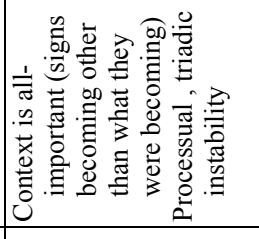 \\
\hline 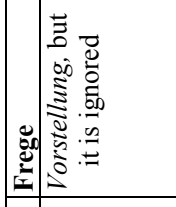 & 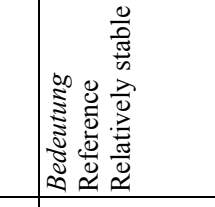 & 竞 & 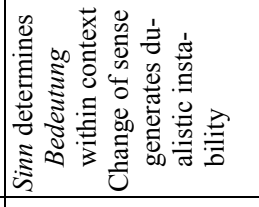 \\
\hline 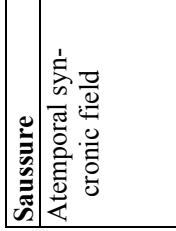 & 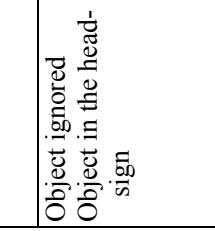 & 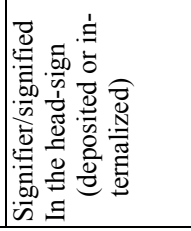 & 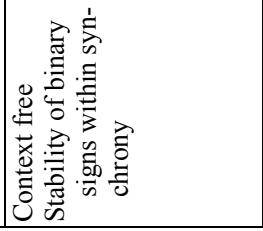 \\
\hline
\end{tabular}




\section{On the pragmatic maxim}

From 1878 until the end of his life, Peirce made various attempts at establishing a general principle to account for meaning. He called that principle the 'pragmatic maxim'. The maxim is the means for constructing the meaning of a sign as a consequence of practical validation of the sign put in the form of a proposition whose nature is that of: (1) a conjecture as to the possible meaning of the sign (Firstness), (3) the conjecture formulated as a hypothesis - what would likely result and render the possible meaning likely, if certain conditions inhere (Thirdness), and (2) the hypothesis put to the test in order to ascertain whether or not the possible meaning is acceptable (Secondness).

Priority is placed on: (1) imagining what might transpire regarding the sign in question when put within the contexts of other signs, (2) conceiving of a viable hypothesis that might be the consequence of the sign's inter-action within that context, and (3) determining the consequences of such practical inter-action. Experience, or sensibility, is the chief watchword: 'Our idea of anything is our idea of its sensible effects'. And the consequence of experience yields a tentative answer to the problem of meaning: 'The possible practical consequences of a concept constitute the sum total of the concept' (EP 2: 139). For Hookway (2004: 121), the maxim must prove the consequence of 'identifying and describing these sensible effects' of the sign - Peirce emphasizes this verificationist theme in his pragmatism when he writes that he only desires

to point out how impossible it is that we have an idea in our minds which relates to anything but conceived sensible effects of things. Our idea of anything is our idea of its sensible effects. (W3: 266)

This is to imply that just as signs become other signs in the continuous semiosic-semiotic process, so also meanings are always becoming something other than what they were becoming, and this becoming is the consequence of a set of initial conditions that are acted on by a potential knower. In Peirce's words:

In general, we may say that meanings are inexhaustible. We are too apt to think that what one means to do and the meaning of a word are quite unrelated meanings of the word 'meaning', or that they are only connected by both referring to some actual operation of the mind. Professor Royce especially in his 
great work The World and the Individual has done much to break up this mistake. In truth the only difference is that when a person means to do anything he is in some state in consequence of which the brute reactions between things will be moulded [in] to conformity to the form to which the man's mind is itself moulded, while the meaning of a word really lies in the way in which it might, in a proper position in a proposition believed, tend to mould the conduct of a person into conformity to that to which it is itself moulded. Not only will meaning always, more or less, in the long run, mould reactions to itself, but it is only in doing so that its own being consists. For this reason I call this element of the phenomenon or object of thought the element of Thirdness. It is that which is what it is by virtue of imparting a quality to reactions in the future. (CP 1.343)

\subsection{How the maxim works}

In Peirce's first rendition of the maxim in 1878, which is the most commonly cited, we have the following:

Consider what effects, that might conceivably have practical bearings, we conceive the object of our conception to have. Then our conception of these effects is the whole of our conception of the object. (CP 5.402; also 5.2, 5.9, $5.18,5.427$, and MS 327)

Notice how a combination of Firstness, Secondness, and Thirdness is implied in the maxim. We are asked to consider the practical bearings of the effects (Secondness) that whatever is under consideration might conceivably have (Firstness) given certain prevailing conditions (Thirdness). Then, we will have what we conceive would be result if the perceived world were of such-and-such a nature, according to what we imagine might possibly be the case (Nesher 1983).

However, since what emerges out of our imaginative faculties is not only unpredictable but virtually without definite limits, the nature of what we would expect will ensue according to the myriad ways our world would be perceived and conceived would be equally unlimited, given all possible times and places, here and there and in the past, present, and future. The maxim, in this regard, plays on our imagining what might possibly be the case in one of an unlimited number of contexts. So there can be no closure, since tomorrow might usher in some unforeseen possibilities of the imagination or of the perceived and conceived world that might end in new probabilities (of Thirdness) of actualization in the world (of Secondness). 
The maxim has to do with the semiotic subject's construction of her world. It is a matter of her making what appears to be the case the case, at least for her at a given space-time juncture. It is a method not for determining whether a set of signs, characteristically in the form of a sentence or set of sentences, is timelessly and undeniably 'true'. Rather, it is an indeterminately variable method for inter-acting with signs in such a way that the 'semiotic world' with which they interrelate appears to be the case. And in the process their meaning emerges: the maxim enables signs — including the semiotic agents, ourselves - to lift themselves up by their own bootstraps.

This is to say that the maxim essentially stipulates that the meaning of a sign regarding what appears to be the case is the product of all conceivable consequences presented by other sentences - and their own consequences - engendered from the original sentence. This product of all conceivable consequences entails the translation of the initial sign or sentence into a series of conditional sentences the antecedents of each of which prescribe certain interactions between the interpreter and the signs in question. The consequences, ideally, consist of observable sign phenomena that should or would make themselves manifest in the event that the original signs or sentences are indeed 'true'.

But 'truth', we repeat, is not the specific goal when applying the pragmatic maxim. The specific task at hand is to draw meaning from the signs being processed by way of their interactive interrelations. The interpreter takes the initial signs and creates a hypothetical situation by imagining what would most likely ensue. Then he puts his hypothetical signs to the test in terms of a thought experiment 'in here' or by interacting with the signs' objects 'out there' in order to see if he was right. If his hypothesis turns out to appear correct for the time being, the possibility nonetheless remains that other hypotheticals may at future moments present themselves, compelling her to repeat the operation. If his initial hypothesis is found deficient, then back to the drawing board for an alternative hypothetical, in which case she repeats the operation. And so on. 


\subsection{The maxim is never infallible}

We should by no means take the maxim as a method to 'perfect clearness', as Peirce's long-time friend, William James put it (James 1920: 411-412; Potter 1996: 94). The maxim is capable of putting us on the road toward clarity, but never perfect clarity. Perfect clarity does not exist for us, since all signs according to Peirce and as we have observed, given their nature as signs, are to a greater or lesser degree caught up in vagueness, for, fallible as we are, there is always some degree of uncertainty in our sign interpretations.

What the maxim does is put us on the track toward some future time when we will hopefully know more than we now know (in other words, our knowing will hopefully be less vague). It tells us to entertain our imagination that so-and-so might be the case of the object, act, or event in questions if certain conditions are in place. The object, act, or event possesses certain characteristics, but at this point they are no more than that: possibilities (Firstness) as far as our awareness goes. None of these possibilities has yet become actual (Secondness) for the sign maker and taker. If and when it is actualized for us, then, and only then, can we properly conceptualize it as a sign (interpretant, Thirdness). In the sense of the futurity of the maxim, then, we have the possibility that, along with our imaginary conception of the matter at hand, we should by the maxim be able to get an idea in terms of what most likely would happen in the event that certain circumstances would be actualized.

In the final analysis, a Peircean meaning of the sign is not a thing or an entity. It is an emergent process resulting from the inter-action between $S-O-I$ within particular contexts. This is to say that a sign's meaning emerges through realizing the consequences of certain interaction between the sign and other signs brought about by the seeker of that sign's meaning. In this manner, it cannot be said that meaning is in the sign, in some talking and thinking head, in the referent of the sign, or in the medium by which the sign is transported to its potential receiver and interpreter. This point was very emphatically made by Hilary Putnam (1975; 1988).

But that is not all. Just as a given interpreter has acquired habits of feeling and sensing and thought within a social context that includes the community to which the interpreter belongs, so also meaning is by no means exclusively an individual affair. Anybody who interprets a 
sign bring the baggage of the entire life of the social conventions by means of which he learned what he knows through habituation of his social practices. This includes past experiences and present experiences that collaborate to create expectations regarding what the future holds in store. Sign meaning, then, also integrates other signs and their own interpreters - since any and all interpreters are signs among signs. It includes the entire community of semiotic agents.

The focus, then rests chiefly on the interpretant $(I)$ of the sign. In principle, it could imply an infinite regress were it not for the interpreter putting a stop to the process by 'cutting' out an $I$ that, in collaboration with $S$ and $O$ that had previously been 'cut' out, produces an effect on the interpreter himself. When the interpreter has interacted with the $S, O$ and $I$, as a result of this effect, he then creates another $S$. This $I$ includes the original sign's meaning, which has become in essence another sign 'cut' from the continuum within this altered context of the interpreter, now having constructed the original sign's interpretation. Since every context of an emergent sign is comparable - but never identical - to past contexts, the sign's interpretation creates a new context in the virtually immediate future, and hence the $S$ becomes something other than what it was in the process of becoming, and so also the $O$, both of which call for mediation by a potentially different $I$. And the triadic process begins anew. In this manner it can be said that Peircean signs are self-correcting (see Ransdell 1977: 162).

\subsection{Meaning in the making within a human context - meaning as form becoming}

As an illustration of meaning change within altering contexts that give rise to the emergence of signs becoming other signs, consider the case of the term 'atom'. 'Atoms' were according to the Greek Democritus minuscule 'solid, indivible spheres'. This is spacetime slice ${ }_{1}$ out of the continuum of semiosic possibilities. During John Dalton's days at the beginning stages of the scientific revolution, when 'atoms' of one substance were conceived to combine with 'atoms' of another substance to form conglomerates or 'molecules', 'atoms' were conceived as solid spheres with minute 'hooks' that could attach one 'atom' with another 'atom' to form a new substance. This is spacetime slice 2 . 
During the later half of the nineteenth century under the influence of Maxwell-Faraday 'field theory', 'atoms' were conceived as microscopic spatial 'vortices': spacetime slice 3 . After John Rutherford discovered in the early years of the twentieth century that 'atoms' actually consisted of collections of 'subatomic' entities, he created the visual image of an 'atom' as akin to a plum pudding, with the 'subatomic' entities embedded in the 'atomic' medium: spacetime slice 4 . Shortly thereafter, Niels Bohr created the picture of an 'atom' as a 'nucleus' surrounded by gyrating 'subatomic' entities, somewhat like a tiny solar system. An 'atom' is in this sense largely 'vacuous': spacetime slice $_{5}$. In the 1920 s Werner Heisenberg proposed that an 'atom' is describable as an abstract mathematical 'matrix', thus doing away with picture theories altogether: spacetime slice 6 . A short time later, the de Broglie-Schrödinger interpretation had it that an 'atom' is a 'wave amplitude'. It becomes substantive only after inter-action with some co-participant entity, which could be the observer through his detecting instrument. In this interpretation, an 'atom' is picturable, if at all, as a hazy cloud of possibilities: spacetime slice.

What, then, is the meaning of 'atom'? If we consider each spacetime slice as a 'world' in and of itself, then each 'world' is a static increment followed by a successive and equally static 'world'. This is the equivalent of McTaggart's (McTaggart, McTaggart 1927) atemporal $B$-series. There is a 'world' before, and a 'world' after. But there is no flow of time. There is no temporal present sliding along the knife edge of time becoming something other than what it was becoming in the past and becoming something that will have been becoming in the future. This temporality would be McTaggart's $A$-series. A Saussurean conception would be akin to the $B$-series. Kripke's 'causal' theory of meaning also ignores process, as does information theory, that focuses on decoding and recoding messages that remain intact when transferred through the sign medium. Frege's concept of meaning renders an account of different interpretations, through time, of sense regarding the same reference, but it does not account for any change of reference as it is conceived within varying contexts. Only the Peircean processual approach to the sign adequately includes the equivalent of McTaggart's $A$-series time.

Peircean meaning, in the final analysis, is indeterminately variable. It is a triadic, context-sensitive, interpreter-dependent, materially extended and embodied dynamic process. As such, it involves inter- 
relatedness and inter-action between signs, their objects, acts and events in the world, and the semiotic agents who are in the process of making and taking them.

\subsection{Implications of the Peircean theory of meaning}

Peirce's theory, outlined in this essay, is of the nature of processual becoming, from possibility (Firstness) to actuality (Secondness) to potentiality (Thirdness in mediation with Firstness and Secondness) as one of the indeterminate number of possibilities, any of which could have been actualized in place of what was selected for actualization). In this sense, account is given of genuine triadic semiosis. Semiosis includes not merely signs of intellection (thought-signs) but also signs of feeling, and inter-related inter-action (bodymind-signs). In this respect, Lakoff and Johnson warrant a favorable nod.

But there is more to this story. It bears on the notion that whatever logic there may be, it cannot be other than multi-valued. And above all, as illustrated in the previous paragraphs, it must include time. The notion of meaning must be non-linearly applied, and change must be allowed. What is meaningful in one spacetime slice can become meaningless in another one, and what is meaningful within one spacetime slice can have emerged from what was meaningful within a previous spacetime slice but has become meaningless within the present spacetime slice. Hence the notion of becoming is all-important. What is becoming does so in the process of present becoming, which was past becoming and will have been future becoming. 'Atoms' as 'solid spheres' eventually became 'atoms' as 'largely vacuous', and those in their own turn became 'cloud-like wave amplitudes'. The concept of becoming is imperative, because all that is semiosis, is flux.

\subsection{Peirce, and the others}

Peirce's view of meaning complements Putnam's (1975; 1981; 1988). Putnam refuses to compromise on his reservations regarding traditional theories of meaning. He emphasizes time and time again that there is no 'God's-eye view' of the world. There is no omniscient grasp of the whole context within which meaning emerges, in all its 
possible ramifications. The world is simply too rich for the poverty of our interpretive capacity. Consequently: (1) Meaning is neither in any correspondence between a sign and its reference, nor is it the case that meaning or sense (Sinn) determines reference (Bedeutung) (contra Frege); (2) Meaning is neither in the brain-mind as an autonomous organism, nor is it in a synchronic slice of language as an autonomous entity (contra Saussure); (3) Meaning is not in the referent that 'causes' stimulation within the brain-mind evoking a certain response to a sign (contra Kripke); (4) Meaning is in the entirety of contextualized bodymind inter-action, but it is not in the solicitation of relatively static schemes (contra Lakoff and Johnson).

The Peircean notion of meaning, in short, can be described as a matter of form-becoming emerging from $S$ to $O$ and from $S$ to $I$ through mediation. This allows us to conceive meaning as a nonsubstantive, co-participatory fluctuating and flowing processual manner. Meaning as form-becoming is an emergent inter-active, interrelational pattern of behavior.

\section{Conclusion}

Thus:

(1) the meaning of a sign depends upon comparable past contexts of what is taken to be the same sign, in the present context, and in imagined, conjectured, or hypothetical future contexts; sign meaning is a time-bound process;

(2) meaning bears on regularity of inter-related inter-action in the form of general modes of behavior guided by habit;

(3) meaning entails a process of imagination, consideration of possible consequences, and inter-action with particular aspects of the physical world — or mental worlds in terms of purely 'thought-signs' — in this sense it is most fundamental to Peirce's 'realist' philosophy;

(4) just as for Peirce it is impossible to think without signs, so also thought itself is impossible without the material incorporation of some

\footnotetext{
6 It bears mentioning that Peirce labels his philosophical posture 'objective idealism'. 'Idealism' in view of the input of imagination as described above, and 'objective' in terms of the sign's, interpretant's and interpreter's inter-action with the object and the object reciprocally with them.
} 
aspect of the world, and meaning is impossible without coparticipation of $S, O$, and $I$ (CP 1.538, 2.253, 5.265, 5.314, 5.470).

When applying this general semiotic approach to biological and social systems, meaning will most often be an interpreter-dependent objective process. It cannot be dissociated from the notion of a situated (and actively distributed) communicational agent (potential or effective). It is both interpreter-dependent and objective because information triadically connects $S, O$, and an effect $(I)$ on the interpreter.

In sum, according to Peirce's pragmatic model, semiosis, is a triadic, dynamic, context-dependent (situated), interpreter-dependent (dialogic), materially extended (embodied) dynamic process. It is a social-cognitive process, not merely a static, symbolic system. It emphasizes process rather than product, development rather than finality. Peirce's emphasis rests not on content, essence, or substance, but, more properly, on dynamics inter-relations.

\section{References $^{7}$}

Adams, Frederick 2003. The informational turn in philosophy. Minds and Machines 13: 471-501.

Almeder, Robert 1980. The Philosophy of Charles S. Peirce: A Critical Introduction. Totowa: Rowman and Littlefield.

Avni, Ora 1990. The Resistance of Reference: Linguistics, Philosophy, and the Literary Text. Baltimore: Johns Hopkins University Press.

Bergman, Mats 2000. Reflections on the role of the communicative sign in semeiotic. Transactions of the Charles S. Peirce Society: A Quarterly Journal in American Philosophy 36(2): 225-254.

Brunning, Jacqueline; Forster, Paul (eds.) 1997. The Rule of Reason. Toronto: University of Toronto Press.

Chisholm, Roderick 1952. Fallibilism and belief. In: Wiener, Philip; Young, Frederic (eds.), Studies in the Philosophy of Charles Sanders Peirce. Cambridge: Harvard University Press, 93-120.

Colapietro, Vincent 1989. Peirce's Approach to the Self: A Semiotic Perspective on Human Subjectivity. New York: State University of New York Press.

Davidson, Donald 1984. Inquiries into Truth and Interpretation. Oxford: Clarendon Press.

Deacon, Terrence 1997. The Symbolic Species: The Co-evolution of Language and the Brain. New York: W.W. Norton \& Company.

7 Acknowledgements. J. Q. thanks The State of São Paulo Research Foundation (FAPESP) for the post-doctoral studies grant n. 02/09763-2. 
- 1999. Memes as signs. The Semiotic Review of Books 10(3): 1-3.

Derrida, Jacques 1974. Of Grammatology. (Spivak, G. C., trans.) Baltimore: Johns Hopkins University Press.

Donnellan, Keith 1972. Proper names and identifying descriptions. In: Davidson, Donald; Harman, Gilbert (eds.), Semantics of Natural Language. Dordrecht: D. Reidel, 356-379.

Donnellan, Keith 1974. Speaking of nothing. Philosophical Review 83: 3-31.

Dummett, Michael 1972. Frege: Philosophy of Language. New York: Harper and Row.

Emmeche, Claus 2003. Causal processes, semiosis, and consciousness. In: Seibt, Johanna (ed.), Process Theories: Crossdisciplinary Studies in Dynamic Categories. Dordrecht: Kluwer, 313-336.

Fetzer, James 1997. Thinking and computing: Computers as special kinds of signs. Minds and Machines 7: 345-364.

- 1988. Signs and minds: An introduction to the theory of semiotic systems. In: Fetzer, James (ed.), Aspects of Artificial Intelligence. Dordrecht: Kluwer Academic Publishers, 133-161.

Fisch, Max 1986. Peirce, Semeiotic, and Pragmatism. Indiana: Indiana University Press.

Fitzgerald, John 1966. Peirce's Theory of Signs as Foundation for Pragmatism. The Hague: Mouton \& Co.

Flower, Elizabeth; Murphey, Murray 1977. A History of Philosophy in America. Vol. 2. New York: Capricorn Books.

Freadman, Anne 2004. The Machinery of Talk - Charles Peirce and the Sign Hypothesis. Stanford: Stanford University Press.

Freeman, Eugene (ed.) 1983. The Relevance of Charles Peirce. La Salle: Monist Library of Philosophy.

Frege, Gottlob 1970. On sense and reference. In: Geach, Peter; Black, Max (eds.), Translations from the Philosophical Writings of Gottlob Frege. Oxford: Basil Blackwell, 56-78.

Hacking, Ian 1993. On Kripke's and Goodman's uses of 'Grue'. In: Stalker, Douglas (ed.), Grue! The New Riddle of Induction. LaSalle: Open Court, 193223.

Harris, Roy. 1987. Reading Saussure: A Critical Commentary on the 'Course de linguistique générale'. LaSalle: Open Court.

- 2002. Saussure and his Interpreters. New York: New York University Press.

Hausman, Carl 1993. Charles Sanders Peirce's Evolutionary Philosophy. Cambridge: Cambridge University Press.

Hoffmeyer, Jesper 1996. Signs of Meaning in the Universe. Indiana: Indiana University Press.

Hookway, Christopher 1985. Peirce. London: Routledge \& Kegan Paul.

- 2002. Truth, Rationality, and Pragmatism - Themes from Peirce. Oxford: Oxford University Press.

- 2004. The principle of pragmatism: Peirce's formulations and examples. Midwest Studies in Philosophy 28: 119-136. 
Houser, Nathan; Roberts, Don D.; Evra, James van (eds.) 1997. Studies in the Logic of Charles Sanders Peirce. Bloomington: Indiana University Press.

Hulswit, Menno 2001. Semeiotic and the cement of the universe: A Peircean process approach to causation. Transactions of the Charles S. Peirce Society: A Quarterly Journal in American Philosophy 37(3): 339-363.

Jakobson, Roman 1980. Linguistics and poetics. In: Sebeok, Thomas A. (ed.), Style and Language. Cambridge: MIT, 350-377.

James, William 1920. Collected Essays and Reviews. Perry, Ralph (ed.). New York: Longmans.

Johansen, Jorgen Dines 1993. Dialogic Semiosis. Indiana: Indiana University Press.

Johnson, Mark 1987. The Body in the Mind: The Bodily Basis of Meaning, Imagination, and Reason. Chicago: University of Chicago Press.

Kripke, Saul 1972. Naming and necessity. In: Davidson, Donald; Harman, Gilbert (eds.), Semantics of Natural Language. Dordrecht: D. Reidel, 253-355.

- 1977. Speaker reference and semantic reference. Midwest Studies in Philosophy 2: 255-276.

- 1980. Naming and Necessity. Oxford: Basil Blackwell.

- 1982. Wittgenstein on Rules and Private Language. Cambridge: Harvard University Press.

Lakoff, George 1987. Women, Fire, and Dangerous Things: What Categories Reveal about the Mind. Chicago: University of Chicago Press.

Lakoff, George; Johnson, Mark 1999. Philosophy in the Flesh: The Embodied Mind and Its Challenge to Western Thought. New York: HarperCollins.

Magnani, Lorenzo 2007. Mimetic minds: Meaning formation through epistemic mediators and external representations. In: Loula, Angelo; Gudwin, Ricardo; Queiroz, João (eds.), Artificial Cognition Systems. Hershey: Idea Group Inc., 327-357.

Merrell, Floyd 1995. Peirce's Semiotics Now. Toronto: Canadian Scholar's Press.

McTaggart, John; McTaggart, Ellis 1927. The Nature of Existence, vol. 2. Cambridge: Cambridge University Press.

Misak, Cheryl (ed.) 2004. The Cambridge Companion to Peirce. Cambridge: Cambridge University Press.

Murphey, Murray 1993. The Development of Peirce's Philosophy. Indianapolis: Hackett.

Nesher, Dan 1983. A pragmatic theory of meaning: A note on Peirce's 'last' formulation of the pragmatic maxim and its interpretation. Semiotica 44(3/4): 203-257.

Parker, Kelly 1998. The Continuity of Peirce's Thought. Nashville: Vanderbilt University Press.

Peirce, Charles Sanders ${ }^{8}$ 1931-1935. The Collected Papers of Charles Sanders Peirce. Electronic edition reproducing vols. 1-6 [Hartshorne, C.; Weiss, P. (eds.), Cambridge: Harvard University Press, 1931-1935]; vols. 7-8 [Burks, A. W. (ed.), Cambridge: Harvard University Press, 1958]. Charlottesville: In-

\footnotetext{
${ }^{8}$ See also footnote 4 .
} 
telex Corporation. [Here referred as $\mathrm{CP}$, followed by volume and paragraph number.]

- 1967. Annotated Catalogue of the Papers of Charles S. Peirce. Robin, R. (ed.). Amherst: University of Massachusetts. [References to manuscripts and letters by Charles S. Peirce - MS and L - are in accordance to this catalogue.]

- 1998 [1893-1913]. The Essential Peirce: Selected Philosophical Writings. Vol. II. Peirce Edition Project. Indiana: Indiana University. [Here referred as EP2, followed by the number of the page.]

Pietarinen, Ahti-Veikko 2005. Signs of Logic: Peircean Themes on the Philosophy of Language, Games, and Communication. (Synthese Library 329.) Dordrecht: Springer.

Potter, Vincent 1996. Peirce's Philosophical Perspectives. Colapietro, Vincent (ed.). New York: Fordham University Press.

- 1997. Charles S. Peirce: On Norms and Ideals. Amherst: University of Massachusetts Press.

Prigogine, Ilya 1997. The End of Certainty: Time, Chaos, and the New Laws of Nature. New York: Free Press.

Prigogine, Ilya; Stengers, Isabelle 1983. Order Out of Chaos: Man's New Dialogue with Nature. New York: Bantam.

Putnam, Hilary 1975. The meaning of meaning. In: Putnam, Hilary, Mind, Language, Reality. Cambridge: Cambridge University Press, 215-271.

- 1981. Reason, Truth and History. Cambridge: Cambridge University Press.

- 1988. Representation and Reality. Cambridge: MIT Press.

Queiroz, Joao; El-Hani, Charbel N. 2006. Semiosis as an emergent process. Transactions of the Charles S. Peirce Society: A Quarterly Journal in American Philosophy 42(1): 78-116.

Ransdell, Joseph 1977. Some leading ideas of Peirce's semiotic. Semiotica 19(3/4): 157-178.

Rescher, Nicholas 1996. Process Metaphysics: An Introduction to Process Philosophy. New York: State University of New York Press.

Rorty, Richard 1979. Philosophy and the Mirror of Nature. Princeton: Princeton University Press.

- 1982. Consequences of Pragmatism. Minneapolis: Minnesota University Press.

Rosenthal, Sandra 1994. Charles Peirce's Pragmatic Pluralism. Albany: State University of New York Press.

- 2000. Time, Continuity, and Indeterminacy: A Pragmatic Engagement with Contemporary Perspectives. New York: State University of New York Press.

Saussure, Ferdinand de 1966. Course in General Linguistics. (Baskin, Wade, trans.) New York: McGraw-Hill.

Shannon, Claude; Weaver, Warren 1949. The Mathematical Theory of Communication. Urbana: University of Illinois Press.

Savan, David 1987-1988. An Introduction to C. S. Peirce Full System of Semeiotic. (Monograph Series of the Toronto Semiotic Circle 1.) Toronto: Victoria College. 
Stampe, David 1979. Towards a causal theory of linguistic representation. In:

French, Peter; Uehling, Theodore Jr.; Wettstein, Howard (eds.), Contemporary Perspectives in the Philosophy of Language. Minneapolis: University of Minnesota Press, 81-102.

Stephan, Achim 1998. Varieties of emergence in artificial and natural systems. Zeitschrift für Naturforschung 53c: 639-656.

Stjernfelt, Frederik (forthcoming). Diagrammatology: An Investigation on the Borderlines of Phenomenology, Ontology, and Semiotics. Dordrecht: Springer.

Thibault, Pierre 1996. Re-Reading Saussure: The Dynamics of Signs in Social Life. New York: Routledge.

Thom, Rene 1975. Structural Stability and Morphogenesis. (Brooks, W. M.; Rand, D., trans.) West Sussex: Ellis Horwood.

Tienne, André de 1992. Peirce's semiotic monism. In: Deledalle, Gérard; Balat, Michel; Deledalle Rhodes, Janice (eds.), Signs of Humanity/L'homme et ses signes. Proceedings of the IVth International Congress/Actes du IVe Congrès Mondial, vol. 3. (Approaches to Semiotics 107.) Berlin: Mouton de Gruyter, 1291-1298.

- 2003. Learning qua semiosis. S.E.E.D. Journal - Semiotics, Evolution, Energy, and Development (3): 37-53.

Tiercelin, Claudine 1995. The relevance of Peirce's semiotic for contemporary issues in cognitive science. In: Haaparanta, Leila; Heinämaa, Sara (eds.), Mind and Cognition: Philosophical Perspectives on Cognitive Science and Artificial Intelligence. (Acta Philosophica Fennica 58), 37-74.

Varela, Francisco 1979. Principles of Biological Autonomy. Amsterdam: NorthHolland.

Waal, Cornelis de 2001. On Peirce. Wadsworth: Thomson Learning.

\section{Семиозис и прагматизм: к динамическому понятию значения}

Философы и представители социальных наук различных ориентаций сошлись во мнении о том, что прагматика семиозиса подходит для динамического описания значения как процесса. Семиозис как центральное понятие прагматической философии Чарльза Сандерса Пирса может стать ключом к давним проблемам, связанным со значением. Действительно, идеи Пирса можно считать плодотворными, если их поместить в рамки когнитивных наук (особенно в связи с его понятием знака). Согласно пирсовской прагматической модели семиозис является триадическим, связанным со временем, чувствительным к контексту, зависимым от интерпретатора, материально протяженным динамическим процессом. Семиозис привносит взаимозависимость и взаимодействие между знаками, их объектами, действиями и событиями, происходящими в мире, и семиотическими агентами, которые являются их отправителями и получателями. 


\section{Semioos ja pragmatism: Tähenduse dünaamilise mõiste suunas}

Erineva orientatsiooniga filosoofid ja sotsiaalteadlased on esile toonud, et semioosi pragmaatika on kohane kirjeldamaks dünaamiliselt tähendust kui protsessi. Semioos kui C. S. Peirce'i pragmaatilise filosoofia kese võib olla võtmeks tähendusega seotud kauastele probleemidele. Tõepoolest, Peirce'i ideid tuleb pidada viljakaiks, kui need paigutada kognitiivteadustesse, eriti seoses tema märgi mõistega. Peirce'i pragmaatilise mudeli kohaselt on semioos triaadne, ajaseoseline, kontekstitundlik, interpreteerijast sõltuv, materiaalse ulatuvusega dünaamiline protsess. Semioos toob kaasa vastastikuse suhestatuse ja vastastikuse toime märkide, nende objektide, tegude ja sündmuste ning semiootiliste toimijate vahel, kes on nende allikaks ja vastuvõtjaks. 